Sharif University of Technology
Scientia Iranica
Transactions B: Mechanical Engineering
IRA I ENTIA

Research Note

\title{
Application of ductile fracture criterion for tensile test of zirconium alloy 702
}

\author{
D.-C. Chen ${ }^{\mathrm{a} *}$, D.-Y. Chang ${ }^{\mathrm{a}}$, F.-H. Chen ${ }^{\mathrm{b}}$, and T.-Y. Kuo ${ }^{\mathrm{a}}$ \\ a. Department of Industrial Education and Technology, National Changhua University of Education, Changhua 500, Taiwan, R.O.C. \\ b. Department of Mechatronic Engineering, National Taiwan Normal University, Taipei, Taiwan, R.O.C. \\ Received 24 September 2016; received in revised form 2 December 2016; accepted 12 February 2017
}

\author{
KEYWORDS \\ Normalized Cockcroft- \\ Latham; \\ Ductile fracture \\ criterion; \\ Zirconium alloy 702; \\ Tensile test.
}

\begin{abstract}
In this study, the critical damage value of normalized Cockcroft-Latham is determined using ductile fracture criterion to define fracture energy. True stress-strain value and materials' properties were obtained by the tensile tests of zirconium alloy 702 and finite-element analysis. It was observed that the maximum value of fractured specimen occurred in the central area of the cross-section, where the highest critical damage value equals 0.649. This paper explored the rarely researched data of zirconium alloys through the inverse analysis method of the FEA. The results were proposed to evaluate the forgeability, and the present study could be used as a basis of designing and developing zirconium alloy. (C) 2018 Sharif University of Technology. All rights reserved.
\end{abstract}

\section{Introduction}

Zirconium alloy 702 has excellent neutron and corrosion resistance and is widely used in the nuclear power plants and chemical industry, such as nuclear reactor and heat exchanger. Previously zirconium alloys have been mostly applied for the national defense and the nuclear industry; however, in recent years, by the development of nuclear electricity generation, rare relevant research data are published on Zirconium alloy.

Due to ductility of this material, it is important to use the appropriate ductile fracture criterion in the calculation of components produced from it.

In numerous studies, tensile tests have been performed to determine the ductile fracture of materials. Pereira et al. [1] compared the mechanical damage of the Marciniak test and the FEA prediction of the steel plate, showing that FEA is effective in

\footnotetext{
*. Corresponding author. Tel.: +886-4-7232105 (ext. 7217); Fax: +886-4-7211287

E-mail address: dcchen@cc.ncue.edu.tw (D.-C. Chen)
}

predicting the material damage. Quan et al. [2] pointed out that, based on the elasto-plastic theory, the finite-element model was established to simulate the drawing limit analysis of AZ31B tube. Komori [3] compared the experiment results of the behaviors of crack propagation through finite-element analysis of different ductile failure theories. Hambli and Reszka [4] provided the fracture criteria identification using an inverse technique method and blanking experiment. Study of Dey et al. [5] indicates that the ballistic limit perforation process can be predicted by JohnsonCook fracture criterion of LS-DYNA software. Zhu et al. [6] used a finite-element model to simulate the fluid-solid interaction in porous materials. Jia et al. [7] investigated microstructure and mechanical properties of 2219 aluminum alloys after solid solution treatment. Chen and You [8] studied the 7075 aluminum maximum damage level, and the experimental process and simulation analysis showed that fracture occurred in the center; so, the results are quite consistent. Cao et al. [9] conducted some research on the finite-element model of three approaches in which ductile damage is used to simulate the ultimate wire drawing and the wire flat rolling processes in cold metal forming. 
Inverse analysis method of FEA by Cho et al. [10] was applied to the ring compression test and the modified limiting dome height test, and then, simultaneously, the flow stress and the friction value can be determined. Joun et al. [11] used a finite-element approach and Hollomon's constitutive law for analyzing tensile tests of low carbon steel through simulation, and thus, the performed analysis can accurately predict the occurrence of necking phenomena. Andrzej and Jacek [12] showed that damage distribution of titanium alloy, Ti6Al4V, was studied by normalized C-L criterion at room temperature.

In this study, tensile tests of zirconium alloy 702 are conducted to determine the true stress-strain state and elaborate on the appropriate ductile fracture criterion, according to the finite-element simulation analysis.

\section{Experimental and finite element analysis}

In this paper, the experiment and simulation analyses of the study is shown in a flow chart as in Figure 1.

The dimensions of the specimens used in the experimental tests are shown in Figure 2. The sheet specimens had a necking made in their center part to excite fracture in the predicted region. The plate specimens were subjected to a tensile test until the ultimate fracture, simultaneously, recorded and measured the damage cross section.

Ductile failure can also be treated as plastic deformation of the nonmetallic material present in the

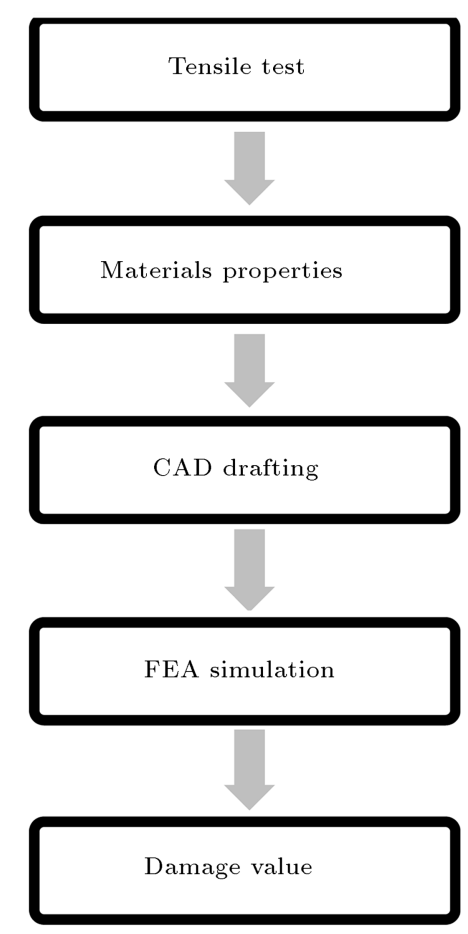

Figure 1. Flow chart of the experiment and simulation.
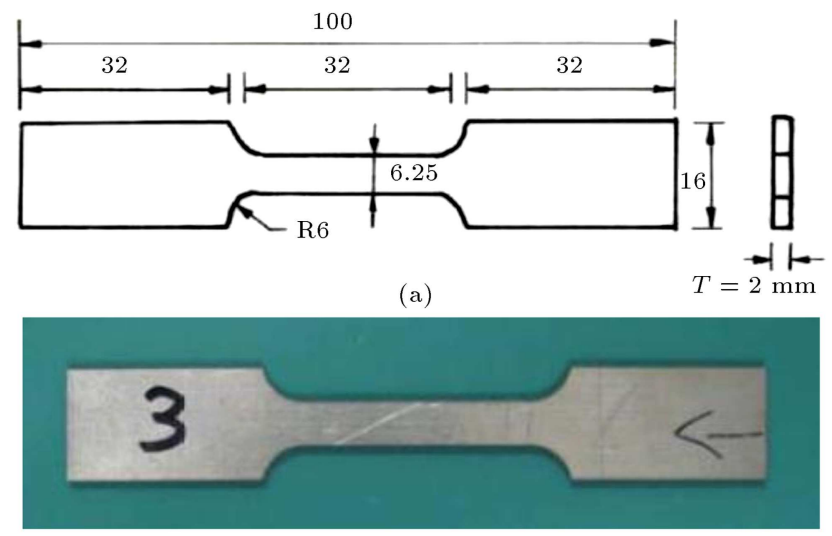

(b)

Figure 2. Specimens used in tests: (a) Dimensions and (b) WEDM (Wire Electrical Discharging Machine).

Table 1. Chemical composition of zirconium alloy 702 .

\begin{tabular}{cccccccc}
\hline \multicolumn{7}{c}{ Chemical composition Wt.\% } \\
\hline Zr+Hf & Hf & Fe+Cr & O & N & C & H \\
Min & Max & & Max & & & Max \\
99.2 & 4.5 & 0.2 & 0.16 & 0.025 & 0.05 & 0.005 \\
\hline
\end{tabular}

inclusions with further precipitation of fine particles, formation of voids, their growth, and the ultimate fracture. Ductile failure is controlled by the processing parameters such as the rate of deformation and molding conditions, lubrication, and friction. In addition, any alterations to the material chemical composition affect its microstructure and uniformity of its surface. Chemical compositions of zirconium alloy 702 are listed in Table 1.

The experimental test results were analyzed using FEA simulations. The simulations were performed using the DEFORM ${ }^{\mathrm{TM}}$ 3D software package, which is widely used for the simulation of rolling, extrusion, upsetting, forging, and other forming processes of metals. This software, whose structure can be subdivided into four modules, such as pretreatment, simulation engine, post processor, and multifunction, provides simulation of the plastic flow stress. The flow stress equation has the following form:

$$
\bar{\sigma}=\bar{\sigma}(\bar{\varepsilon}, \dot{\varepsilon}, T)
$$

where $\bar{\varepsilon}$ is strain, $\dot{\varepsilon}$ is strain rate, and $T$ is temperature.

The maximum damage value obtained and the value corresponding to the critical damage of the material can be used to predict the ductile behavior of crack originating from the molding damage. Deform simulation software's built-in failure criteria include Cockcroft-Latham, normalized Cockcroft-Latham, Oyane, Borrzo, Rice and Tracey, etc. This article has only considered Cockcroft-Latham and Normalized Cockcroft-Latham failure criteria, which will be explained as follows. 
An energy function integral of the maximum tensile stress and effective strain proposed by Cockcroft and Latham define the timing of the occurrence of a material fracture. It is considered that a material fracture occurs when maximum tensile strain energy in unit volume reaches the critical damage value, as shown by Eq. (2):

$$
\int_{0}^{\bar{\varepsilon}_{f}} \sigma_{\max } d \bar{\varepsilon}=C_{*}
$$

where $\sigma_{\max }$ is maximum tensile stress, $\bar{\varepsilon}_{f}$ is limit fracture strain, $\bar{\varepsilon}$ is effective strain, and $C_{*}$ is CockcroftLatham critical damage value.

Chen et al. [13], based on Cockcroft and Latham ductile failure criteria, pointed out that a material fracture is related to the effective stress of deformation. The material forming limit is defined as a fracture energy, which is the product of an effective deformation and a normalized ratio from the maximum stress divided by effective stress.

Chen et al. introduced the normalized CockcroftLatham criterion, reducing it to the dimensionless form of Eq. (3):

$$
\int_{0}^{\bar{\varepsilon}_{f}} \frac{\sigma_{\max }}{\bar{\sigma}} d \bar{\varepsilon}=C
$$

where $\bar{\sigma}$ is effective stress and $C$ is the normalized Cockcroft-Latham critical damage value.

\section{Results and discussion}

To determine the plastic flow stress of zirconium alloy 702 , the materials of the model were obtained from the database of the software used. Figures 3-5 display the finite-element mesh of tensile test simulation (10000 elements, tensile velocity $1 \mathrm{~mm} / \mathrm{sec}$ ), where before loading, during loading, and after fracture are shown.

Figures 6 and 7 display the effective strain diagram, revealing that the maximum effective strain

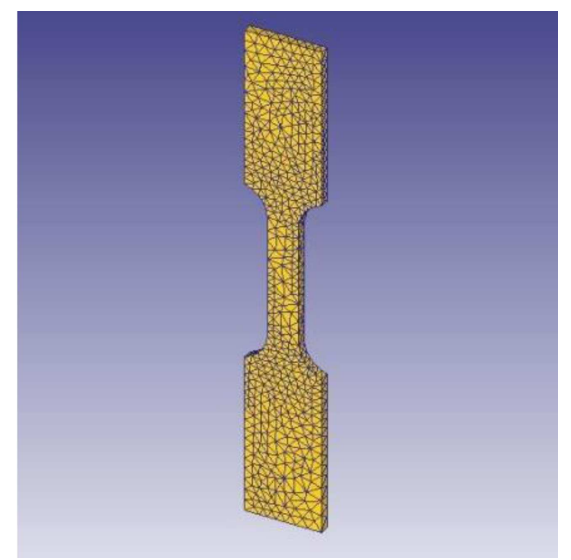

Figure 3. Finite-element mesh before tensile. occurs in the middle zone, which corresponds to the maximum strain value, and it is the most susceptible to fracture. Figures 8 and 9 display the effective stress diagram, where the points with the maximum stress and strain are assumed to be coincided, thus producing

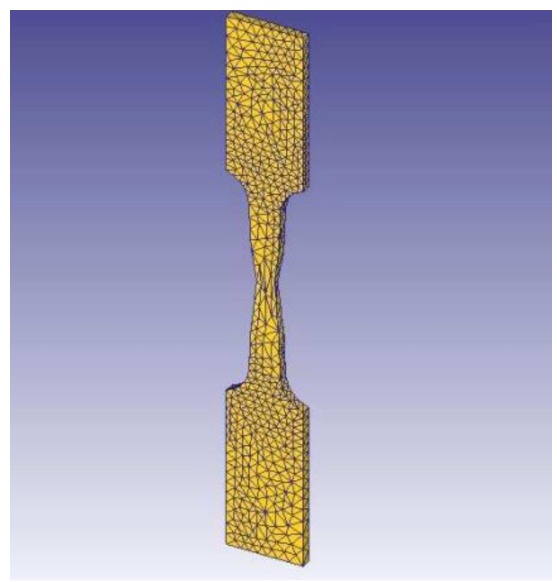

Figure 4. Finite-element mesh during tensile.

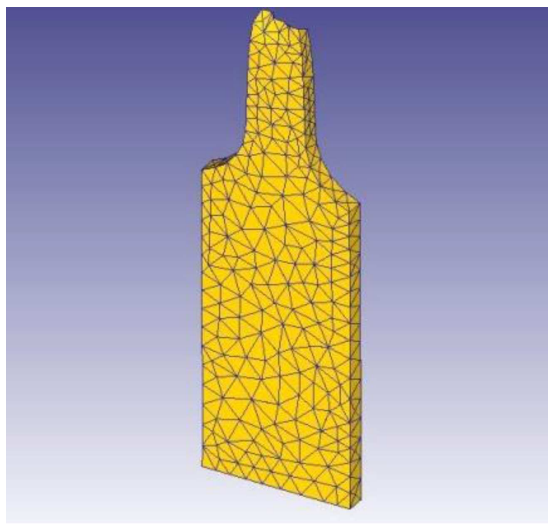

Figure 5. Finite-element mesh after fracture.

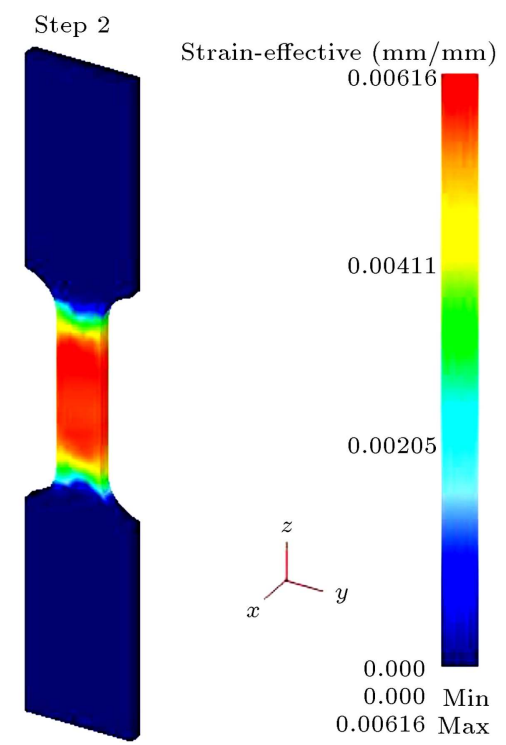

Figure 6. Initial tensile effective strain. 

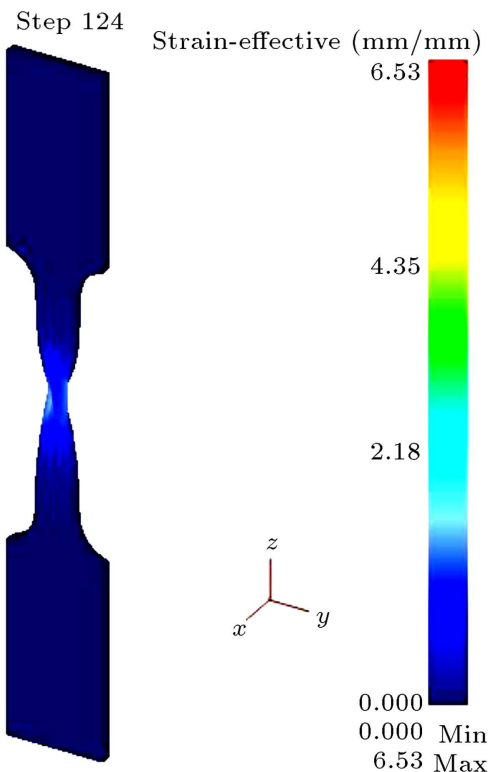

Figure 7. Final tensile effective strain.
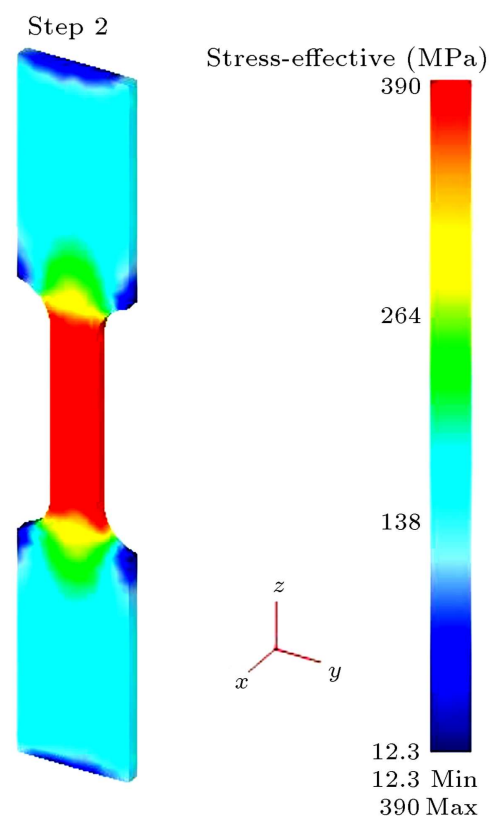

Figure 8. Initial tensile effective stress.

stress concentration points from which cracks may originate.

Figures 10-12 display the distribution of critical damage value of tensile test process. The following are initial tensile, middle tensile process, and final fracture, respectively. As can be seen in Figures 10 to 12 , the critical damage value, affected by the influence of tensile action, sustained an increase in the middle region which is particularly evident. Figure 13 depicts the experimental and simulated fracture patterns, which show a good correlation. The integral was calculated at characteristic points in the specimen cross sections.

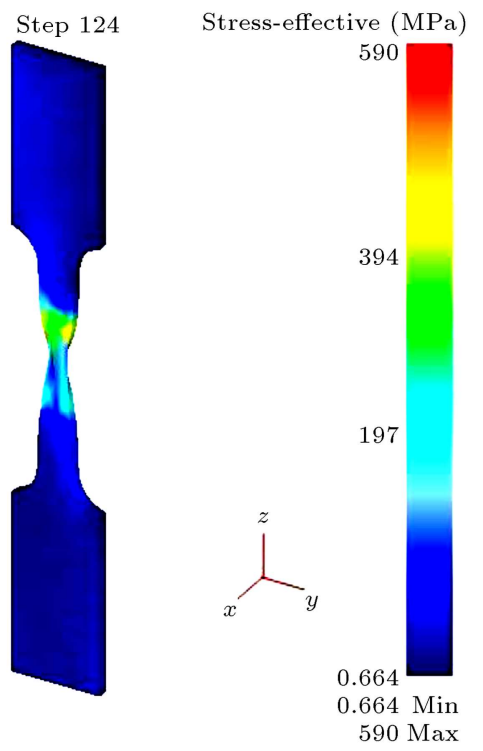

Figure 9. Final tensile effective stress.

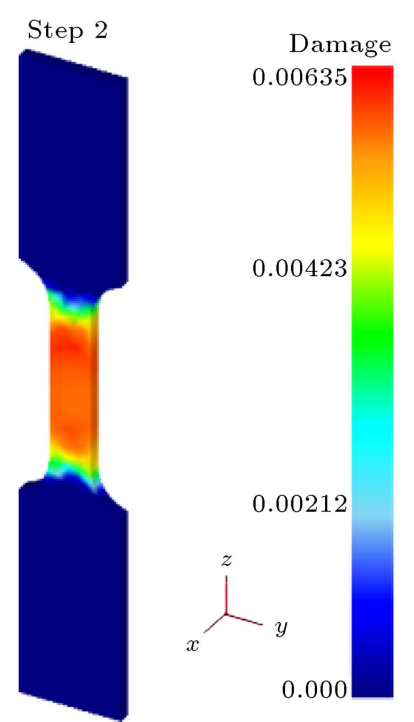

Figure 10. Damage value of initial tensile.

Figure 14 displays the critical damage value of specimen and the points during the tensile testing of the specimens. The critical damage value of the normalized Cockcroft-Latham is listed in Table 2. It was observed that fracture specimen's the maximum value occurred in the central area of the cross section. The highest critical damage value $C$ equal to 0.649 was taken to be the limit value, determining fracture under experimental conditions.

Table 2. The critical damage value of the normalized Cockcroft-Latham.

\begin{tabular}{cc}
\hline Point & Critical damage value \\
\hline 1 & 0.649 \\
2 & 0.635 \\
3 & 0.553 \\
\hline
\end{tabular}




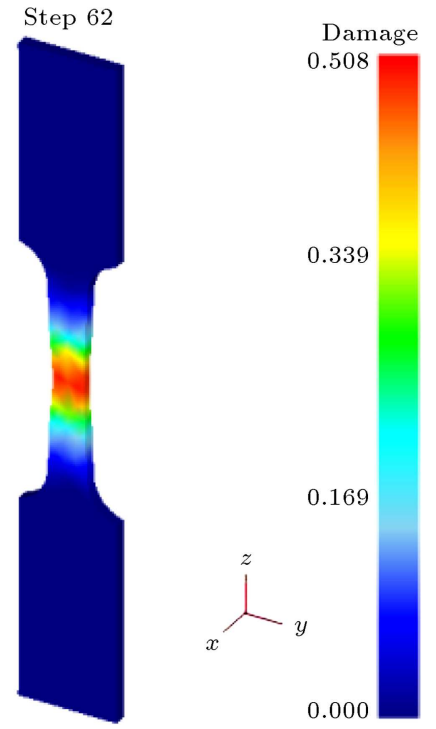

Figure 11. Damage value of middle tensile process.

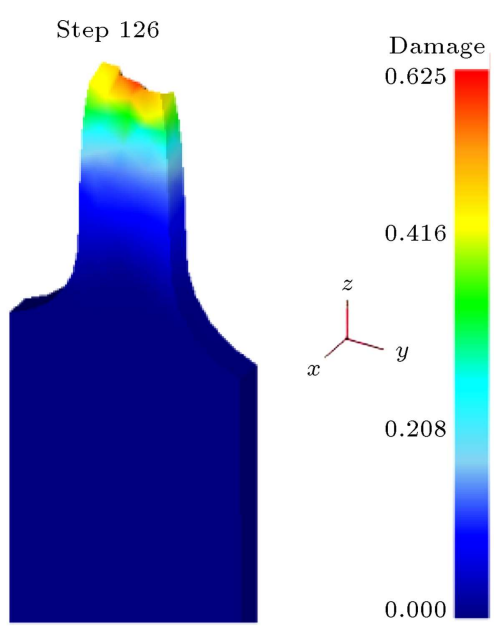

Figure 12. Damage value of final fracture.

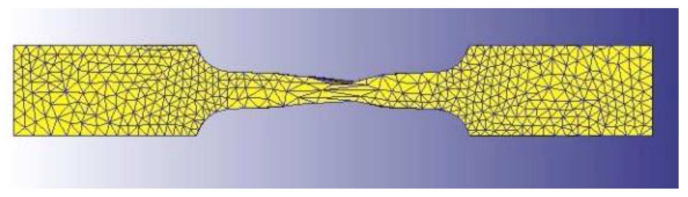

(a)

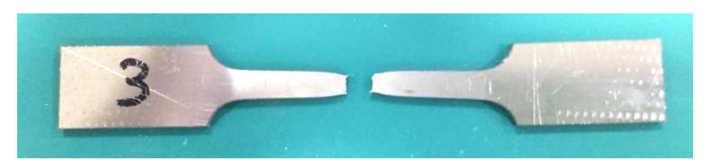

(b)

Figure 13. Zirconium alloy 702 fracture situation: (a) Simulation and (b) experiment.

\section{Conclusions}

The results show that the critical damage value of normalized Cockcroft-Latham can be obtained using the ductile fracture criterion and FEA software. True stress-strain value and materials properties were ob-

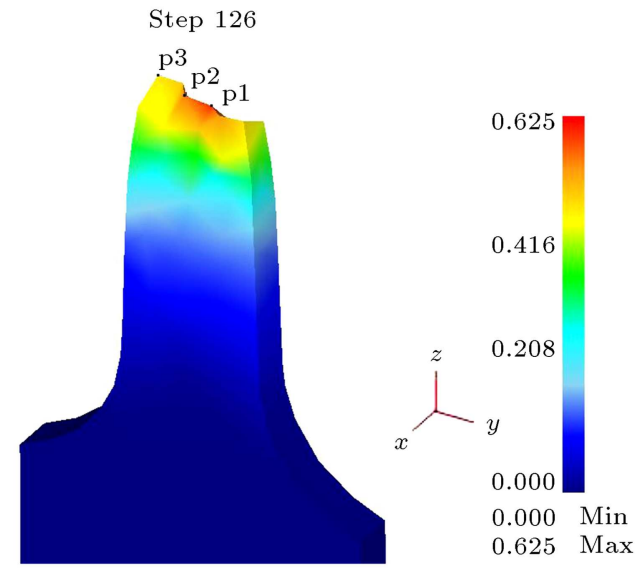

(a)

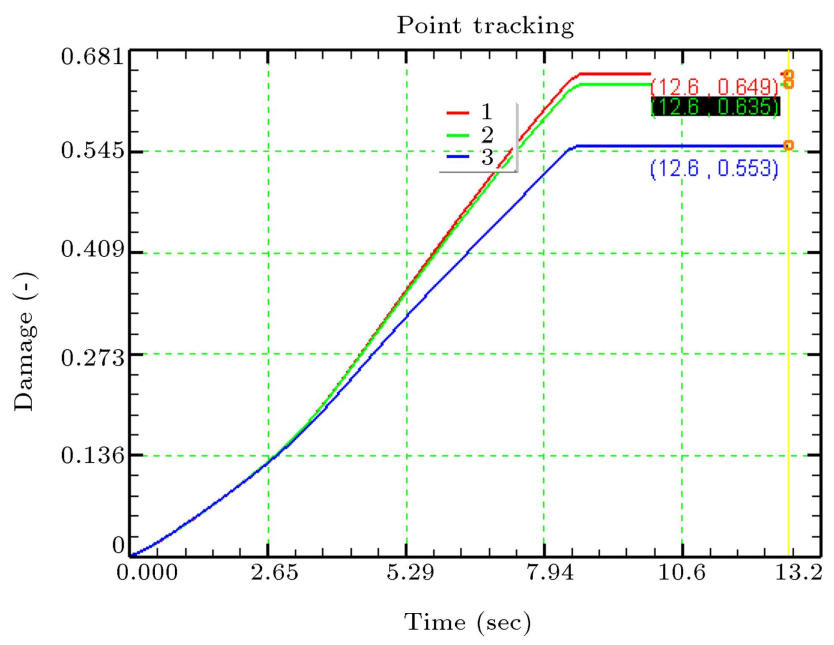

(b)

Figure 14. Critical damage value: (a) Tensile fracture in analysis point and (b) measure value of characteristic position.

tained from the tensile tests of zirconium alloy 702 and finite-element analysis. Factors affecting ductile fracture, such as effective stress, effective strain, and damage, were analyzed. It was observed that fracture specimen's the maximum value occurred in the central area of the cross section, and the highest critical damage value was equal to 0.649. Finite-element analysis as applied to zirconium alloy 702 fracture criteria can be used for rolling, extrusion, upsetting, and forging of the materials.

\section{References}

1. Pereira, I.M., Rubi, M.G., and Acselrad, O. "Comparison of the experimental and the numerically predicted mechanical damage in the sheet forming of steel", $J$. Mater. Process. Technol, 203(1-3), pp. 13-18 (2008).

2. Quan, G.Z., Tong, Y., and Chen, B. "A constitutive description for drawing limit of magnesium alloy tube based on continuum damage mechanics", Mater. Sci. Forum., 610-613, pp. 951-954 (2009). 
3. Komori, K. "Effect of ductile fracture criteria on chevron crack formation and evolution in drawing", Int. J. of Mech. Sci., 45(1), pp. 141-160 (2003).

4. Hambli, R. and Reszka, M. "Fracture criteria identification using an inverse technique method and blanking experiment", Int. J. of Mech. Sci., 44(7), pp. 13491361 (2002).

5. Dey, S., B $\varnothing$ rvik, T. Hopperstad, O.S. and Langseth, M. "On the influence of fracture criterion in projectile impact of steel plates", Comput. Mater. Sci., 38(1), pp. 176-191 (2006).

6. Zhu, Q.J., He, Y.F. and Yin, Y. "Finite element analysis of deformation mechanism for porous materials under fluid-solid interaction", Mater. Res. Innovations., 18, pp. 22-27 (2014).

7. Jia, S.F., Zhan, L.H., and Zhang, J. "Influence of solid solution treatment on microstructure and mechanical properties of 2219 aluminum alloy", Mater. Res. Innovations., 18, pp. 52-58 (2014).

8. Chen, D.C. and You, C.S. "Fracture criterion for the tensile test of 7075 aluminum alloy", Strength of Materials., 47(1), pp. 122-127 (2015).

9. Caoa, T.S., Bobadillab, C.P., Montmitonneta, P., and Boucharda, P.O. "A comparative study of three ductile damage approaches for fracture prediction in cold forming processes", J. Mater. Process. Technol., 216, pp. 385-404 (2015).

10. Cho, H., Ngalle, G., and Altan, T. "Simultaneous determination of flow stress and interface friction by finite element based inverse analysis technique", CIRP Annals - Manufacturing Technology, 52(1), pp. 221224 (2003).

11. Joun, M., Choi, I., Eom, J., and Lee, M. "Finite element analysis of tensile testing with emphasis on necking", Comput. Mater. Sci., 41(1), pp. 63-69 (2007).

12. Andrzej, G. and Jacek, P. "Determining the normalized Cockcroft-Latham criterion for titanium alloy Ti6Al4V in tensile testing at room temperature",
Proceedings of the World Congress on Mechanical, Chemical, and Material Engineering (MCM 2015), Paper No. 248, Barcelona, Spain (2015).

13. Chen, C.C., Oh, S.I., and Kobayashi, S. "Ductile fracture in axisymmetric extrusion and drawing", Journal of Engineering for Industry., 101, pp. 36-44 (1979).

\section{Biographies}

Dyi-Cheng Chen is presently a Professor in National Changhua University of Education, Taiwan. He received his $\mathrm{PhD}$ degree in Mechanical Engineering at the National Sun Yat-sen University, Taiwan (2003). His current interests include metal forming (extrusion, forging, drawing, rolling), engineering education, material properties, FEM, and metal cutting.

Dong-Yao Chang graduated from the Department of Industrial Education and Technology from National Changhua University of Education, Taiwan (2005). He received his MS degree in Mechanical Engineering at the National Central University, Taiwan (2007). He is presently a $\mathrm{PhD}$ student in National Changhua University of Education. His current interests include metal forming, material properties, and metal cutting.

Fei-Hsiang Chen was born in 1984, Taiwan. He obtained his BS and MS degrees in Mechatronic Engineering in 2006 and 2009, respectively. He is presently a PhD student in National Taiwan Normal University. His research interests include zirconium alloy, welding metallurgy, and mechanical properties of materials.

Tsung-Ying Kuo graduated from the Department of Industrial Education and Technology from National Changhua University of Education, Taiwan (2015). He is presently an MS student in National Changhua University of Education. His current interests include metal forming and FEM. 